\section{Biological psychiatry and reductionism}

SIR: Karlsson \& Kamppinen (1995) suggested that biological psychiatry is in a "confused state" partly because it lacks a "sound conceptual framework", and partly because "the levels of organisation are not explicated with sufficient clarity" in modern biological psychiatry. They hypothesised that the concept of "emergent materialism" clarifies problems associated with reductionism in biological psychiatry. The presupposition of emergent $m a$ terialism that "everything is material" (Karlsson \& Kamppinen, 1995) is untenable, because it disallows the non-material, irreducible concept of "intentionality," which all human behaviour and existence presupposes (Polanyi, 1958; Merleau-Ponty, 1962). Issues such as intentionality, meaning, and freewill are likely to prove problematic for biological psychiatry for some time to come.

KARLSSON, H. \& KAMPPINEN. M. (1995) Biological psychiatry and reductionism. Empirical findings and philosophy. British Journal of Psychiatry, 167, 434438

Merleau-Ponty, M. (1962) Phenomenology of Perception. London: Routledge and Kegan Paul.

Polyani. M. (1965) The structure of consciousness. Brain, 88, 799-810.

University of New Mexico

Albuquerque, New Mexico 87131, USA

AUTHORS' REPLY: From the viewpoint of emergent materialism, intentionality is truly the toughest feature of the world, as Mr Daniel points out quite correctly. The Austrian philosopher (and the founder of phenomenology) Franz Brentano aptly characterised the appearing reality as divided into two mutually exclusive regions: physical and psychological phenomena. The latter is intentional, the former is non-intentional (Sajama \& Kamppinen, 1987). Materialistic and naturalistic philosophies like the one we are expounding - try hard to get rid of such absolute dichotomies. We think that modern naturalists like John Searle or Daniel Dennett have proposed elegant solutions. They construe intentionality as a biological property, which is, in principle, no more mysterious than other higher-level biological properties like, for example, digestion (Revonsuo \& Kamppinen, 1994). Searle and Dennett differ from each other in that Searle seems to think that intentionality has interesting lawful properties of its own (Searle, 1992), whereas Dennett thinks that personal level intentionality is reducible into sub-personal information processing (Dennett, 1991, 1995). We think - on the basis of empirical evidence - that the level of intentionality is lawful and worth studying. We agree that intentionality will prove to be a highly problematic issue in biological psychiatry. However, in emergent materialism, intentionality and other such features are treated as challenges, not as mysteries.

Dennetr, D. (1991) Consciousness Explained. Harmondsworth: Penguin Books.

- (1995) Darwin's Dangerous Idea. New York: Simon \& Schuster Revonsuo, A. \& Kamprinen, M. (eds) (1994) Consciousness in Philosophy and Cognitive Neuroscience. Hillsdale NJ: Lawrence Erlbaum Associates.

Sajama, S. \& Kamppinen, M. (1987) A Historical Introduction to Phenomenology. London: Croom Helm.

SEARLE, J. (1992) The Rediscovery of the Mind. Cambridge MA: MIT Press.

\section{Department of Cultural Studies \\ University of Turku \\ FIN-20500 Turku, Finland}

Department of Psychiatry

H. KARLSSON

University of Turku

FIN-20700 Turku, Finland

M. KAMPPINEN

\section{Antipsychotic drug-induced dysphoria}

SIR: We have reviewed the paper of King et al (1995) in our journal club. In our view the study has a number of serious flaws that invalidate its conclusions. The flaws are:

(1) Absence of a control group. This is important given that the rate of adverse placebo effects can be as high as 25\% (Grahame-Smith \& Aronson, 1992).

(2) The absence of blind investigators and subjects.

(3) The study population was inadequately defined, particularly in terms of their knowledge of the effects of haloperidol.

(4) Dysphoria was not defined and objective rating scales were not used.

Non-compliance with medication is a major cause of relapse in psychotic illness, and any factor which may influence it warrants investigation. Antipsychotic drug-induced dysphoria might well be such a factor but this area deserves more rigorous investigation than that described by King et al.

Grahame-Smith, D. G. \& Aronson, J. K. (1992) Oxford Textbook of Clinical Pharmacology and Drug Therapy (2nd edn). Oxford: Oxford University Press. 
KING, D. J., Burke, M. \& LuCas, R. A. (1995) Antipsychotic drug-induced dysphoria. British Journal of Psychiatry. 167, $480-482$.

R. GRAY

C. BROWN

R. HOOGHAMER

A. LEE

Wonford House Hospital

S. OXBORROW

Exeter EX2 $5 A F$

AUTHOR'S REPLY: Gray et al make a number of criticisms which would, of course, be valid had ours been a prospective study. It was, however, submitted as a Brief Report and was an account of clinical observations made in the course of two pharmacokinetic studies. It was reported because it was probably the largest single series in healthy volunteers ( 51 subjects) to be published, and because of the high and consistent incidence of dysphoria (an unpleasant and subjective mood state characterised by irritability, hostility, fear, tension, panic, impatience or vaguely described distress) on the two study days $(40 \%)$.

The aims of the report were to remind clinicians not to miss or dismiss this symptom in their patients, to illustrate that dysphoria can occur independently from akathisia and to note that the "neuroleptic threshold" is unlikely to be any different in patients and volunteers after acute dosing (McEvoy et al, 1991).

McEvoy, J. P., Hogarty, G. E. \& Steingard, S. (1991) Optimal dose of neuroleptic in acute schizophrenia. A controlled study of the neuroleptic threshold and higher haloperidol dose. Archives of General Psychiatry. 48, 739-745.

The Queen's University of Belfast

D. J. KING

97 Lisburn Road

Belfast BT9 7BL

\section{Bias towards chronicity in schizophrenia?}

SIR: The conclusions of 13 years follow-up study by Mason et al (1995) raise important questions as much about the course of schizophrenia as to the 'bias' of the professionals. The conclusion "only $17 \%$... achieve complete recovery over the longer term" appears biased for the following reasons. It appears that mental health professionals are not willing to consider the illness of schizophrenia in a manner that general medicine considers illnesses like hypertension, diabetes, arthritis. The above three illnesses and many others with 'no cure' do not lead to 'complete recovery'. However, doctors working with non-psychiatric illnesses emphasise and focus on abilities rather than disabilities. The diabetic with food restriction among other limitations, the hypertensive with activity restriction, do not consider themselves as 'disabled' and learn to live near normal lives. All of them need help and care but they are not seen as 'Chronic' in the way we present the course of schizophrenia.

There are three implications for a revision of the 'non-recovery' approach to schizophrenia. Firstly, a medical approach to describe course would draw greater support for patients, research and professional work. Secondly, there is need to embark on a series of new studies with first episode patients to delineate how far chronicity is a function of events occurring after the onset of illness (early recognition, early treatment, adequate family and community support, rehabilitation in the community, lack of stigma etc.) rather than an essential part of the illness. Thirdly, for those of us working in developing countries, the difference in the approach of 'treatability' could prove decisive in terms of support from the planners and people for mental health programmes. This is especially true for the acceptance of the integration of mental health with primary health care which is the current focus of mental health care in developing countries. A shift in 'bias' of mental health professionals may be timely?

Mason, P., Harrison, G., Glazabrook, C., et al (1995) Characteristics of outcome in schizophrenia at 13 years. British Journal of Psychiatry, 167, 596-603.

National Institute of Mental Health

R. SRINIVASA MURThY and Neurosciences

P.O. Box 2900

Bangalore-560029

India

AUTHORs' REPLY: We agree with Murthy's point that 'disability and chronicity' have been overemphasised in describing the outcome in schizophrenia, and that this pessimistic outlook is unlikely to be in the best interests of our patients. However, there are many authors who share a more optimistic view about the outcome of schizophrenia. Zubin et al (1983) suggested that the course of schizophrenia has undergone a 'benign metamorphosis' over the second half of this century, and Harding et al (1987) demonstrated good symptomatic outcome (no further signs or symptoms of schizophrenia) in $68 \%$ of their 20-25 year follow-up of 'chronic hopeless' cases of DSM-III schizophrenia. In a previous paper (Harrison \& Mason, 1993) we commented on the hypothesis that outcome in schizophrenia has undergone a 'benign metamorphosis'. We suggested 